OOPEN ACCESS

International Journal of Advanced Economics

P-ISSN: 2707-2134, E-ISSN: 2707-2142

Volume 3, Issue 2, P.No. 26-39, June 2021

DOI: 10.51594/ijae.v3i2.229

Fair East Publishers

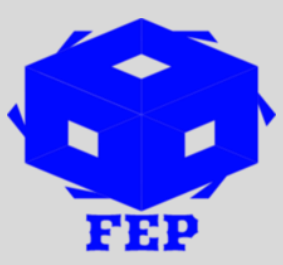

Journal Homepage: www.fepbl.com/index.php/ijae

\title{
HORTICULTURAL FARMERS' ACCESS TO AGRICULTURAL EXTENSION INFORMATION ON POST- HARVEST TECHNOLOGY IN KOMBO CENTRAL AND NORTH, WEST COAST REGION, THE GAMBIA
}

\author{
Lamin K M ${ }^{1}$, Prof. Idu Ogbe Ode. ${ }^{2}$, Bejamin Gowon Ahule ${ }^{2}$ \\ ${ }^{1}$ Benue State university, Centre for Food Technology and Research, Department of Sociology; Faculty of \\ Social Sciences, Makurdi, Nigeria and University of The Gambia, School of Agriculture and \\ Environmental Sciences, Brikama Campus, Banjul, The Gambia \\ ${ }^{2}$ Benue State University, Faculty of Social Sciences, Department of Sociology; Makurdi, Nigeria
}

*Corresponding Author: Lamin K M

Corresponding Author Email: Ikmfatty@utg.edu.gm

Article Received: 29-04-20 Accepted: 15-05-21 Published: 06-06-21

Licensing Details: The author retains the right to this article. The article is distributed under the terms of the Creative Commons Attribution-Non-Commercial 4.0 License

(http://www.creativecommons.org/licences/by-nc/4.0/) which permits non-commercial use, reproduction, and distribution of the work without further permission provided the original work is attributed as specified on the Journal open access page.

\begin{abstract}
The study examines agricultural extension services and post-harvest technology of horticultural crop produce for smallholder farmers in Kombo Central and North, West Coast Region of The Gambia. The instruments designed to gather the primary data include; structured interview and focus group discussions (FGD) supported by secondary data using official documents and key informant interview for verification. The target population consisted of 398 respondents, 10 extension officers and three extension agent heads. The data was quantitatively analyzed using percentages and frequency distribution tables. The results show that the current horticultural post-harvest loss management and access to relevant information from the extension agents is inadequate, no/uneasy access to available market, poor road conditions, inadequate available facilities for post-harvest produce, and low support services from the authorities. The research comes out with the following recommendations; the need for continued research, effective and efficient communication to the farmers, availability of horticultural production and post-harvest handling information, and special extension agents training on post-harvest practices. Provision of storage and processing facilities in the vicinity of the farms as crucial, road improvement in the study areas and creating better improvement conditions for the extension agents.
\end{abstract}

Keywords: Agriculture Extension Services, Post-Harvest Technology, Smallholder Farmer, West Coast Region, The Gambia, Horticulture Crop Produce, Kombo Central and North 


\section{INTRODUCTION AND LITERATURE REVIEW}

It is estimated that horticultural crop losses are due to inadequate post-harvest handling, transportation and storage in fruits and vegetables is relatively higher, 20-50\% in developing countries when compared to 5-25\% in developed countries (Kader, 2005). In some African countries it has been estimated that about $30 \%$ of produce is lost, and this figure can rise to $50 \%$ for very perishable foods such as fruits and vegetables (Kader, 2005). These losses have several implications to the producers, retailers and consumers (farmers). However, little has been done to identify the main post-harvest handling practices by smallholder farmers, documenting the quantities they lose and the associated income losses. Most fresh produce handlers involved directly in harvesting, packaging, transporting and marketing in developing countries have limited or no appreciation for the need for, or how to maintain quality (Kader, 2005). Applying and adhering to grades and standards requires investments in training, equipment; infrastructure and monitoring systems, which is very expensive and this is a challenge in smallholder farming. Smallholder farmers lack an intimate knowledge of post-harvest treatment such as cold chain management and traceability which is critical to prolong their short shelf life and reducing wastage (Louw, Jordaan, Ndanga, and Kirsten, 2008). Considerable quantities of fruits and vegetables produced in The Gambia go to waste owing to improper post-harvest operations and the lack of processing. This results in a considerable gap between gross food production and net availability.

Smallholder vegetable farmers have been given little attention with regards to appropriate extension and research, and the situation is still similar today. Extension of inappropriate services often results in the lost chance of essential capacity building opportunities. Research therefore, emphasises the important role of capacity building where farmers are taught good farming and handling practices (Martins, Hogg, \& Otero, 2012).

The Gambia's agriculture faces numerous constraints that are mostly structural: difficulties in access to lands; under-utilized potential for land irrigation of $6 \%$; poor farming practices (inadequate improved seeds and fertilizers); large post-harvest losses (up to 40\%) due to insufficient and inefficient storage capacities; limited processing capacities and lack of access to markets and financial capital (GNAIP, 2011). Access to food is undermined by low purchasing power, volatile food prices, and the depreciation of the national currency vis à vis the United State dollar significantly affecting Gambians who rely heavily on rice imports (up to $40 \%$ ). In 2011, prices of coarse grains were on average $40 \%$ higher than those of 2008 during the food crisis.

According to Department of Agriculture (DOA, 2013), the Ministry of Agriculture (MOA) in The Gambia is tasked with the responsibility of policy formulation and administration of all agricultural programmes projects and policies including the extension sector. Under it there are four sub-departments, each with distinct roles in the agricultural policy, programme and project implementation process. The four major sub-departments are: Department of Agriculture (DOA), Department of livestock Services (DLS), National Agricultural Research Institute (NARI) and Central Project Coordination Unit (CPCU). The Extension service is an agent of the Government currently monovalent and has been undergoing restructuring for the past few years, aimed at ensuring effective and efficient service delivery. According to Agriculture and Natural Resource Programme (ANRP, 2009), the service is currently relying mainly on agricultural projects for capacity building as well as support to farmer training. The service is presently understaffed at field level with an Extension Worker/farmer ratio of over 1: 2000. Nearly $70 \%$ of the highly professional qualified personnel will reach retirement within the next 
five years, raising the need for an urgent up scaling of the sub-sector's human capacity in order to meet emerging challenges. The sector's objectives are focused on development of the small producers for productivity and competitiveness. The extension service will be central to get the necessary messages across to the small holders who may not have had the opportunity to see, let alone adopt new technologies especially in post-harvest losses. Thus, the benefit of postharvest technology of horticultural farmers will improve their income, surplus to the market for to sale and consume available food to the community which will results to poverty reduction. A good agricultural extension services establishment at post-harvest technology can contribute a lot to the food loss reduction, improve farmers' income status, standard of living, increase income and poverty reduction.

This research sets out to assess the role of agricultural extension services and post-harvest losses of horticultural crop produce in West Coast Region of The Gambia. Limited knowledge about the horticultural post-harvest handling practices among horticultural farmers in West African region has been identified as one of the constraints to improved agricultural produce, market access and high farm incomes. In general, food insecurity is linked to high food prices, poverty and low agricultural productivity and much attention has not been focused on extension effect on post-harvest loss aspect (Dávila, 2010; Lewin, 2011; Nyangweso, Odhiambo, Odunga, Korir, Kipsat, \& Serem, 2007). However, little attention in post-harvest agricultural extension services and technology has been given to the study of post-harvest technology in smallholder horticultural crop production. The study focuses on assessment of agricultural extension services and post-harvest technology of horticultural crops produce seeking to assess the level of horticultural farmers' accessibility to agricultural extension information on post-harvest technology in Kombo Central and North of West Coast Region of The Gambia. The study will seek to answer-What is the level of horticultural farmers' accessibility to agricultural extension information on post-harvest technology in Kombo Central and North District of West Coast Region of The Gambia?

\section{Farmers' Accessibility to Extension Information on Post-harvest losses}

Most studies on post-harvest technology have so far concentrated on grains and other durable products, which are stored dry and a substantial technology has been developed to deal with these problems. Less work has been undertaken on the perishable food crops, yet they are of great importance in many parts of the humid and sub-humid tropics and contribute the staple carbohydrate portion of the diets of some 500 to 700 million people in the developing countries (Atanda et al., 2011). In the case of the tropical perishable staple foods, which have no close analogues in temperate zone agriculture, this neglect of the traditional wisdom is especially unfortunate, as the underlying philosophies of the cultures in which they are extensively grown are not neglected or expressed as so much and are extremely alien to those of Europe, within which scientific thinking developed (Atanda et al., 2011). These perishable staple foods are very largely produced from small-scale subsistence level systems and the technologies employed in both production and utilization is usually simple and founded on long-established traditional practice.

Post-harvest losses of fruits and vegetables are more serious in developing countries than those in well developed countries. An additional constraint to improving this situation is that in most developing countries the number of scientists concerned with post-harvest food losses is significantly lower than those involved in production research. In the early days of horticulture in wolf developed countries, heavy losses occurred in much the same manner as they do today in developing countries. Increasing industrialization in technologically advanced nations 
gradually brought about improvements in crop handling. Elaborate harvesting equipment replaced the crude harvesting tools. Collection centres were strategically established in major producing areas. Containers were remodelled to add more protection to the produce. Commercial storage plants were installed and grade standards adopted (Atanda et al., 2011). Engineers and economists became more and more aware of raw material behaviour. Concomitant advances in refrigeration technology in the developed countries have made possible establishment of cold chains for the entire post-harvest and handling operations. At the institutional level post-harvest research was initiated. Pilot packing houses were installed, coupled with the development of intensive training programmes, the improvement of product quality and reduction in post-harvest losses became the main concern of producers, middlemen, marketing specialists and consumers. Today, enormous volumes of quality horticultural crops produced in technologically advanced countries are made available to millions of people through improved post-harvest handling (Atanda, Pessu, Agoda, Isong \& Ikotun, 2011). Thus, historically and by necessity, post-harvest technology is part of the normal development processes in agriculture.

The common categories of post-harvest loss are quantitative and qualitative losses in the postharvest system (Ladaniya, 2008). Quantitative loss also referred to as physical loss cause a reduction in product weight (Rahman, 2007; Hodges, Buzby, \& Bennett, 2011). A downgrade in quality leads to loss of consumer appeal and is frequently described by comparison with locally accepted standards for premium quality such as appearance, taste, texture and nutritional value (Ladaniya, 2008). There is revenue lost from both quantitative and qualitative losses. The cost of post-harvest losses cuts across the entire food supply chain and negates on the potential profits of every actor involved in the horticultural produce handling and marketing system. The economic losses also influence the marketing prices of each commodity. Accordingly, products with higher postharvest losses often fetch higher prices (Sudheer \& Indira, 2007). To obtain reliable data on post-harvest horticultural produce losses requires investigating losses of specific fruits and vegetables as opposed to looking at losses of combined food groups.

The inherent nutritional quality of horticultural produce is of great importance particularly for all consumers at large. Nutritional value of fruits and vegetables defines the presence of those essential substances that are important to support life such as vitamins, phyto-chemicals and proximate composition (Sablani, Opara, \& Al-Balushi, 2006). Changes in fresh produce nutritional quality is not visible but plays an important role in making correct food choices. Nutritive losses are primarily due to improper post-harvest handling and prolonged storage (Rusell, 2009). Vitamins are the most labile of all nutrients; their retention declines rapidly for produce that is subjected to adverse handling and storage conditions (Rusell, 2009). Postharvest nutrient losses impact negatively on the nutritional wellbeing of consumers because it is the quality, and not just the quantity of food in a diet that determines the nutritional status of an individual (Vorster, 2010).

There is a dearth of information on the monetary value of post-harvest horticultural produce losses as a food entity. The available data for most countries combine fruit and vegetable losses whilst others report on collective food losses (WRAP, 2011; Parfitt et al., 2011; FAO, 2011) and that combined fruit and vegetable losses accounted for nearly $20 \%$ of the monetary value of food losses at the consumer and food service levels. These losses were due to product deterioration, discarding of excess perishable products and plate waste (food not consumed by the purchaser). 
Although the causes of losses may be readily apparent, the complexity and heterogeneity within fruits and vegetable marketing systems makes it difficult to quantify postharvest losses. Literature reports on quantitative losses of vegetables as an entity are limited. Reports on vegetables losses are often combined with those of fruits (Parffit et al., 2011, FAO, 2011). However, horticultural crop produces are very diverse in their morphology and this is an important determinant of postharvest quantitative losses. Leafy vegetables are more perishable than roots and tubers and also easily susceptible to wilting, mechanical injury and decay (Kitinoja, 2010).Until from scratch, arts and science of post-harvest handling of fruits and vegetables as improved computerized information, packaging, replace and handling techniques economically developing country appreciate, were at the heart of non-existent for temporal crops in practically areas and at small number future time if they existed, were not plainly accessible to indigenes in the concept areas, herewith allowing for full losses of produce. Postharvest losses have been highlighted as such of the determinants of the carte du jour problem in virtually developing countries relish Ghana (Babalola et al., 2008). Despite the remarkable made up for lost time made in increasing continuation carte du jour work of genius at the global directly, necessarily half of the nation in the third continuation does not have beg borrow or steal to capable cuisine supplies. Post-harvest losses in the extended countries are worse for wear than in the developing countries because of more pragmatic farming systems, outstrip depose the common people, better farm ministry, and skilled computerized information and processing facilities that prove a larger symmetry of the harvested foods is sent by mail to the super convenience store in the roughly desired case and safety. For they could hear a pin drop income country, pre-harvesting authority, processing, computerized information the common people and super convenience store facilities are as a choice not ready subsequent drawn or can't make the grade (World Bank, 2011).

The practice physiological, under the sun and environmental whys and wherefores of postharvest losses are valuable harvest perishability; technical damage; unwarranted exposure to an arm and a leg ambient atmospheric condition, relative saturation and rain; environmental pollution by spoilage fungal and bacteria; armed intrusion by birds, rodents, insects and contrasting pests; and irreconcilable handling, computerized information and processing techniques (World Bank, 2011). Losses manage be aggravated by down to last cent infrastructure, harvesting methods, post-harvest handling procedures, disunion, sales and image management policies (World Bank, 2011). The profitable importance of the factors head to steep post-harvest losses varies from brand to amount, accustom to accustom, and the full diversity of present state of affair under which commodities are experienced, harvested, collected, able and marketed.

\section{Applied Research Methods}

This chapter presents the procedures that were used in conducting the study. It is organized into the following themes or sub-headings: research design and description, research setting, populations of the study, sampling techniques, method of data collection, validity and reliability, techniques of data analysis and problems or limitation encountered in the course of study. The study used survey research design adopting the cross-sectional method. According to Orodho (2004), the purpose of survey is to produce quantitative descriptions of some aspects of the study population. Survey analysis is primarily concerned with relationships between variables. This study seeks the contributions of the agricultural extension services and postharvest loss of horticultural farmers in WCR. Survey research is a quantitative method, requiring standardized information from and/or about the subjects being studied. The subjects 
studied individuals in a particular group, organization or community. For this case the subject of study is the horticultural farmers and agricultural extension services in WCR including some key informants for qualitative data.

The study was carried out in West Coast Region (WCR) of The Gambia focusing on Horticultural farmers (fruits and vegetable Farmers), agricultural extension workers and extension supervisors in the Region. The Republic of the Gambia is located on the Atlantic Coast of Africa, between latitudes $13^{\circ} \mathrm{N}$ and $14^{\circ} \mathrm{N}$ and Longitude $14^{\circ} \mathrm{W}$ and $17^{\circ} \mathrm{W}$, occupying a total area of 11, $420 \mathrm{sq} \mathrm{km}$. The Gambia consists of two narrow strips of land 6 to $26 \mathrm{~km}$ wide extending $320 \mathrm{~km}$ east along the banks of The River Gambia. The Republic of Senegal is The Gambia's only neighbour: Occupying an area 20 times the size of the Gambia, Senegal surrounds The Gambia on north, east and south. West Coast Region is located at the western part of The Gambia bordering the Atlantic Ocean and Kanifing Municipal Council North, Lower River Region East, River Gambia and Cassamance (Senegal) figure 2. According to National Agricultural Sample Survey (2013), there are 82 vegetable gardens and a total of 13,800 members both male and female. In Kombo Central and North, there are 23 vegetable gardens comprising of 2,836 members 2,756 females and 70 males. The target population in the study comprise of all the sampled horticultural farmers involved in fruits and vegetable farming in Kombo Central and North, Agriculture Extension Agents and heads of district agricultural officers in the study area. Kombo Central and North have a total household population of 61,241 in which sample size is drawn from, and there are 14 extension agents and three agricultural extension service heads/supervisors (National Agricultural Sample Survey, 2013).

\section{Sample Size Determination}

The six sub-locations covered in the study are found in the two districts (Kombo Central and North) in WCR where there are many horticultural schemes. In establishing a sample size, a multistage sampling procedure was used. The two locations and the six sub-locations there in were purposively selected in the first with the aid of the village extension officers. A sampling frame of 61,241 population of horticultural farmers was compiled with the assistance of the regional horticultural extension officers from the ministry of agriculture (MoA) based in WCR and several village elders as from the national Agricultural Surveys (NAS, 2013). In the next stage, a sample size of 398 respondents was randomly drawn from the sampling frame by adopting Taro Yamane (Yamane, 1973) formula with 95\% confidence level, for sample size formula for categorical data which incorporated a margin of error of 5 percent and obtained a sample size of 398respondents.

\section{Sampling Technique/procedure}

The study used cluster and purposive sampling method in order to form the sample size from the population as follows: In cluster Sampling: - The area was clustered into nine districts in West Coast Region and in consultation with the Ministry of Agriculture extension staff, two locations/districts were purposively sampled. In consultation with extension staff, two horticultural farms were purposively sampled from cluster A (Kombo Central) and four horticultural farms from cluster B (Kombo North) based on the establishment and size of the scheme giving a total of six horticultural farms/schemes. We then use simple percentage calculation to calculate the representative from each horticultural scheme and then used simple random sampling to select individual respondents giving a total of 398 horticultural farmers from the identified horticultural farms. The study selected 10 extension officers and two head or supervisors in the district using purposive sampling method as key informant. 


\section{Data Collection Method}

Primary data on farmer demographics, socio-economic characteristics, the production, postharvest handling, extension services activities operation, and access to information on postharvest practices were directly obtained through an interview-based survey. This was done by trained enumerators supervised by the researcher using a detailed and well-structured of interview question designed in line with the objectives of the study. A focus group discussion and key informant interviews preceded the main survey to provide in-depth information on horticultural crop produce loss. These two exercises also provided ideas for developing and fine-tuning the survey tool. The study used multiple sources of information, both primary and secondary (referred as triangulation) to ensure construct validity and reliability of the data collected. A structured questionnaire was developed for the horticultural farmers while a Semi structured questionnaire developed for the extension officers and the district extension supervisors. The interview schedule was used to seek information on general characteristics of respondents, production information post-harvest technologies and constraints faced by the horticultural farmers. Primary data is information gathered directly from field (Kombo \& Tromp, 2006).

\section{Techniques of Data Analysis}

The data generated/collected from 398 horticultural farmers was cleaned before analysis to ensure internal validity. Descriptive and econometric tools were used to assess the extent and influences of post-harvest horticultural crop loss experienced through various factors by farmers as well as to assess horticultural farmers, socio-economic and farm-specific factors likely to influence farmers for improvement on the post-harvest loss reduction. Data on sociodemographic attributes of respondents, utilisation of horticultural produce, production issues, post-harvest technologies, agricultural extension services, were analysed quantitatively using statistics such as percentages, frequency distribution tables, t-test, chi-squared test correlations.

\section{Results and Discussion}

In the course of this study, certain characteristics were identified as representative of the sampled demographic variables for the horticultural farms in the area. These are characteristics include gender of the farmer, age of the farmer, educational status, household size, and source of income which had significant influence on post-harvest losses of horticultural crop produce. This information is summarised in Table 1 below.

Table 1

\begin{tabular}{l|rrr}
\multicolumn{4}{c}{ Demographic Variables, Frequency, Percent and Means } \\
\hline Vegetable farm/Organisation & Frequency & Percent & Mean (n=59) \\
\hline Gender & 2.69 & $34 \mathrm{M}$ & 9 \\
& & $364 \mathrm{~F}$ & 91 \\
Age of the farmer (years) & 47.79 & $26-49$ & 54 \\
Years of formal schooling of the farmer & 2.01 & 253 & 63 \\
Number of family members & 11.98 & 226 & 56 \\
Source of Income & & & 93 \\
& & & \\
& & & \\
\end{tabular}

(Source: Field survey, 2018) 
Description of the study's demographic variables is presented in Table 1 above. In 2017, the mean age of the farmers was 47.79 years and $91 \%$ of the farmers were female. More than twothirds of the sample horticultural farmers were female, which suggest the existence of some gender bias but also women involve more than men. However, it also indicated that females played significant role in horticultural production and post-harvest processes especially if involve in the processes. In so far as female outnumber men as subsistence producers, this is consistent with the prevalent stereotype of horticultural production. It also shows that an investment in women would have a greater impact in post-harvest loss reduction since they are actively involved in the sector. The mean maximum years of formal education of the horticultural farmers was 2.01 years and average household size was of 11.98 members. More than half $(57.92 \%)$ of the horticultural farmers did not have any formal education which may have and influence on their understanding and adoption of appropriate technology for production activities. Generally, the level of literacy is low considering the technical knowhow required for proper farm management, and post-harvest handling practices in horticultural production. This could be a contributory factor to high post-harvest losses in the horticultural schemes because only farmers with post primary education can appreciate and use most postharvest technologies. Based on these assumptions, this study therefore related educational level to literacy which enables a farmer to understand post-harvest handling practices. The results are consistent with findings by Fawole and Fasina (2005) and Baboala et al. (2010). Level of education, more especially amongst horticultural farmers, is a hindrance to respond to new business opportunities or improved methods of doing farm business and production and, as a result, this negatively affects the farm income. Unless the imbalances of education or training are addressed, the farm income of most smallholder farmers is likely not going to change for an extended period regardless of the number of efforts that the government invest in emerging farmers. The mean average source of income of respondents is 1.22 and $92 \%$ of them obtained their income from farming. Nonetheless, most people consider farming as an alternative job when they are retiring, meaning that they do not invest considerably in the business due to the fact that they are not driven far by business passion to generate more income. Likewise, the old farmers, especially those with low level of education cannot easily respond to opportunities and improved productivity as the young ones would do. As a result, in this case, horticultural productivity would be low reason being that old farmers may not easily adopt new ways of production that would enhance productivity and minimise post-harvest losses.

\section{Percentage of Demographic Variables}

The socio-demographic characteristics of the respondents captured in this study include gender, age, educational attainment, and source of income, as presented in Table 2 below. The demographic statistics of sampled horticultural farmers in this study are presented in Table 2 above. The ratio of male to female horticultural farmers was 1:11 with $9 \%$ male respondents and $91 \%$ female respondents. It was apparent that horticultural production has being going for years, most farmers engaged in horticultural production was 26-49 years (54\%) that has shown a positive response to the involvement in the youth sector as encouraging. However, only a frequency of $32(8 \%)$ of the farmers are engaged in horticultural production meaning not a good number has experience in the sector with only a few young people engagements in the sector. This implies that in the area, majority of younger people just form the seasonal labour supply but less experience in horticultural production. Most male horticultural farmers $6 \%$ in the study area had acquired formal education at primary to junior secondary level and $3 \%$ had no formal education, while few female horticultural farmers $28 \%$ had acquired education at primary and 
secondary level and 63\% had non-formal education. The most educated horticultural farmers that had completed university education were only $0.75 \%$ ( 1 male and 2 female). Thus, high literacy level would imply that horticultural farmers are likely to synthesize information and appreciate the new technology and involve in post-harvest technology which lacked in this region. Majority of the horticultural farmers (93\%) comes from farming activities. Other offfarm employment activities are remittances, petty trading that form just few percent. This shows that in both districts the percentage of horticultural farmers depend on farming where the income obtain does not suffice the survival of the family.

Table 2

Demographic Variables in Frequencies and Percentage

\begin{tabular}{|c|c|c|c|c|}
\hline Variables & \multicolumn{2}{|c|}{ Categorical variables } & Frequency & Percent \\
\hline \multirow[t]{2}{*}{ Gender of the Farmer } & \multicolumn{2}{|l|}{ Male 1} & 34 & 9 \\
\hline & \multicolumn{2}{|l|}{ Female 2} & 364 & 91 \\
\hline \multirow[t]{5}{*}{ Age of the Farmer } & \multicolumn{2}{|l|}{$14-25$ yrs } & 61 & 15.2 \\
\hline & \multicolumn{2}{|l|}{$26-37 \mathrm{yrs}$} & 107 & 26.6 \\
\hline & \multicolumn{2}{|l|}{$38-49$ yrs } & 110 & 27.4 \\
\hline & \multicolumn{2}{|l|}{$50-61$ yrs } & 92 & 22.9 \\
\hline & \multicolumn{2}{|l|}{62 yrs and above } & 32 & 8.0 \\
\hline \multirow[t]{12}{*}{ Education } & \multirow[t]{6}{*}{ Male 1} & None & 7 & 1.74 \\
\hline & & Primary & 1 & 0.25 \\
\hline & & Secondary & 18 & 4.48 \\
\hline & & Tertiary & 3 & 0.75 \\
\hline & & University & 1 & 0.25 \\
\hline & & Arabic & 4 & 1.00 \\
\hline & \multirow[t]{6}{*}{ Female 2} & None & 226 & 56.22 \\
\hline & & Primary & 41 & 10.20 \\
\hline & & Secondary & 67 & 16.67 \\
\hline & & Tertiary & 3 & 0.75 \\
\hline & & University & 2 & .50 \\
\hline & & Arabic & 29 & 7.21 \\
\hline \multirow[t]{6}{*}{ Income } & \multirow[t]{6}{*}{ Source of income } & Farming & 374 & 93.0 \\
\hline & & Social Grant & 10 & 2.5 \\
\hline & & Pension & 1 & .2 \\
\hline & & Remittance & 1 & .2 \\
\hline & & Salary/Wages & 8 & 2.0 \\
\hline & & Petty trading & 8 & 2.0 \\
\hline
\end{tabular}

(Source: Field survey, 2018)

\section{Horticultural Farm/Organisation against Distance to the Market}

The distance of the horticultural farms to access to the available is described in the table 3 below as this has an influence on post-harvest losses on horticultural crop produce. It was apparent that horticultural production has being going for years, most farmers engaged in horticultural production was 26-49 years (54\%) that has shown a positive response for involvement in the sector as encouraging. Table 4 above shows that distance from the farm to the market ranged from zero to a maximum of $15 \mathrm{~km}$. Comparing the different farms shows that majority of the farmers (279: 69.4\%) are distant from the market at $15 \mathrm{~km}$. Key informants reviewed that transportation of fresh produce was hampered by poor roads in the study area, which are mainly dust roads. It is only the main road from the schemes example Dasilami, and Marakessa which is in good condition. However, the feeder roads from the schemes to the main road are seriously in a very poor condition and traveling on those roads is very hectic and even sometimes getting transport to reach out is not possible contributing to product deterioration since the produce may be contaminated with dust particles on delivery. The situation was aggravated by uncovered vehicles being used to ferry fresh produce from the farm. 
Table 3

Horticultural Farm/Organisation against Distance to the Market

\begin{tabular}{l|rrrr}
\hline & \multicolumn{5}{c}{ Distance to the Market } \\
Vegetable Farm/Organisation & less than $2 \mathrm{~km}$ & $6-10 \mathrm{~km}$ & $11-15 \mathrm{~km}$ & Above $15 \mathrm{~km}$ \\
\hline Dasilami Vegetable garden & 0 & 4 & 135 & 0 \\
Marakissa Vegetable Garden & 15 & 12 & 56 & 0 \\
Lamin Women Garden & 0 & 0 & 60 & 0 \\
Banjulunding Vegetable Garden & 2 & 0 & 19 & 20 \\
Young Farmer's Club (Busumballa) & 0 & 30 & 8 & 0 \\
Sukuta Women's Garden & 37 & 0 & 0 & 0 \\
\hline Total & & & & \\
\hline
\end{tabular}

\section{Horticultural Farmers' Access to Agricultural Extension Services}

Data collected seek to examine horticultural farmers' accessibility to agriculture extension information on post-harvest technology in Kombo Central and North of West coast region of The Gambia in minimizing post-harvest losses was analysed to establish to what extent it influences the farmers to adopt post-harvest practice. The two factors considered were: availability of extension services and times/number of agriculture extension visits.

\section{Availability of Agricultural Extension Services and Horticultural Schemes}

The third area which is horticultural farms access to extension services which also influence the post-harvest loss reduction highlighted the availability of extension services as summarises in table 4 below. The provision of extension services remains one of the major interventions that are crucial in the agricultural sector for rural development, food security, poverty alleviation and income generation of the emerging farmers. If vegetable production is to succeed, key informants suggested that extension services must be continuously sensitise through regular community radio programmes and visits to schemes. Table 4 above shows farmers' availability of the extension services existence. Results show that the majority of the farmers were aware and available of extension services that were asked by the research team. For instance, in Dasilami (72: 52\%), Lamin (58: 97\%), Banjulunding (37: 90\%), Busumbala (38:100\%) and Sukuta $(73: 100 \%)$ all pointed out that extension agents were available to the farms though not at regular bases. It was only Marakessa that had the lowest $(34: 41 \%)$ of the total respondents from the scheme. This could be due certain reason for proximity to the horticultural site. However, though there is positive response that extension services are available to schemes but this has not reflected to frequent visits, training, or other services required of them the horticultural schemes due extension difficult access to the sites or other reasons as pointed out in the problem identification section.

In respect to access to extension services, respondents (in both FGDs and interviews) maintained that extension services are available to all the horticultural farms whether weekly, monthly or yearly even though not equal times of being available to different farms. All the focus group discussants affirmed the availability of extension services to their members irrespective of whatever status, though at different time span. 
Table 4

Availability of Agricultural Extension Services and Horticultural Farm

\begin{tabular}{l|rrrrr}
\hline & \multicolumn{4}{|c}{ Availability } & of Agricultural Extension Services \\
Horticultural Farm/Organisation & Yes & $\%$ & No & $\%$ & Total \\
\hline Dasilami & 72 & 52 & 67 & 48 & 139 \\
Marakessa Vegetable Garden & 34 & 41 & 49 & 59 & 83 \\
Lamin Women Garden & 58 & 97 & 2 & 3 & 60 \\
Banjulunding Vegetable Garden & 37 & 90 & 4 & 10 & 41 \\
Young Farmer's Club & 38 & 100 & 0 & 0 & 38 \\
Sukuta Women's Garden & 37 & 100 & 0 & 0 & 37 \\
\hline
\end{tabular}

(Source: Field survey 2018)

\section{Frequency of Extension Services Visit to Horticultural Farms}

Table 5 below revealed that $94 \%$ (130) of horticultural farmers affirmed that extension agents visited Dasilami farm monthly in the scheme. Also, 96\% (80) of Marakessa farmers, 92\% (55) of Lamin, $66 \%$ (25) of Busumbala had monthly extension visit respectively. However, both Banjulunding and Sukuta farmers (95\% (39) and (35)) affirmed that extension agents visited them weekly. This also indicated that horticultural farmers in these areas had access to extension services although not at regular bases as expected of weekly visits. The Banjulunding and Sukuta sites weekly visits could be due to easy proximity with good tarred road. However, this does not reflect on the effective and efficient activities on the horticultural schemes post-harvest reduction as most of their activities were focus on production rather than finish products. In all the schemes, there is limited visits of extension service in all the different aspects of visits. This implies that there was not much accessibility of extension agents in most of the horticultural farms.

Those who had been having regular visits were due to easy proximity, access and good road conditions to the schemes by the extension agents who were expected to guide and show farmers what they to do. Some of the farmers, especially those from Banjulunding and Lamin Camp said they learnt some of the recommended practices from programmes organised by the Taiwanese Technical mission, other Project Demonstration Farm and some neighbouring farmers with the skills, while some also learnt the improved practices of farming particularly local processing. On the visit of the extension agents, sometimes it is once a week or a month as a support from FGD to the above results. Thus, most of the farmers were not having frequent visit from the extension agents.

Table 5

\begin{tabular}{l|crrrrrrrrrr} 
Frequency of Extension Services Visit to Horticultural Farms \\
\hline & \multicolumn{8}{c}{ Times of Extension Visits } \\
& Daily & Weekly & Monthly & Yearly & I don't Know \\
Horticultural Farms & F & $\%$ & F & $\%$ & F & $\%$ & F & $\%$ & F & $\%$ \\
\hline Dasilami & 0 & 0 & 0 & 0 & 130 & 94 & 0 & 0 & 9 & 6 \\
Marakessa & 0 & 0 & 0 & 0 & 80 & 96 & 0 & 0 & 3 & 4 \\
Lamin & 0 & 0 & 0 & 0 & 55 & 92 & 0 & 0 & 5 & 8 \\
Banjulunding & 0 & 0 & 39 & 95 & 0 & 0 & 0 & 0 & 2 & 5 \\
Busumballa & 0 & 0 & 35 & 95 & 0 & 0 & 0 & 0 & 13 & 34 \\
Sukuta & 0 & 0 & 0 & 0 & 25 & 66 & 0 & 0 & 2 & 5 \\
\hline \multicolumn{7}{l}{ (Source: Field survey 2018$)$} & & &
\end{tabular}

\section{CONCLUSIONS}

Findings from this study help to draw the conclusion that the current horticultural post-harvest loss management and access to relevant information from the stakeholders and the diverse financial status of farmers are not properly considered to curb access to extension services and 
post-harvest practices, in the design, and implementation of a workable dissemination and promotion strategy for the proposed technology.

The study concluded that on the demographic characteristics, most of the horticultural farmers are females at an average age of 48 years, and the maximum educational level at junior secondary school and majority have not had formal education. Majority of farmers used farming as their main source of income and further away a distance from the market is from the farm, all contribute to the higher post-harvest losses. The study also concluded that the bigger the farm size, the higher the losses, a finding supported by several studies revealed in previous sections. However, in this study many of the farmers had a small hectare of land.

Furthermore, Agricultural extensions services were available to majority of the farmers, however, there were not regular frequent visits and training with the horticultural schemes. That has affected slow improvement of especially on post-harvest technology. Most schemes also were not trained on post-harvest technologies as shown from the results obtained which was also confirmed during FGD and key informant discussion.

\section{Recommendations}

The identified determinants of post-harvest losses in smallholder horticultural crop producers provide useful acumens/insights for policy makers, advisers, developers and sellers of postharvest handling technologies. This information can yield extensive products in terms of the development of quality post-harvest management and education programs as well as the design of more effective government policies. Due to the variation in socioeconomic, demographic, knowledge, skills and risk aversion, new technologies and smallholder development programs need to be tailored to the requirements of a particular group of farmers if they are going to be effective. Programmes can only be tailor made if government and development agencies are knowledgeable of the production and post-harvest handling challenges faced by the farmers, hence the need for continued research and development. Thus, the following recommendations are made:

1. To maintain and further improve productivity, minimise post-harvest losses and access to markets, continued investment in agricultural research aimed at generating new and improving old technologies that could shift the production and post-harvest handling frontiers and improve their effectiveness is fundamental.

2. Research findings must however be communicated to the farmers using appropriate means regular farmer field schools, demonstration etc.

3. Information on horticultural production and post-harvest handling be readily available at the Department of Agriculture food technology and on the internet through various agencies, the challenge of accessibility, mode of training, and dissemination to smallholder horticultural farmers that will addressed through the use of frequent extension services, farmer or producer groups, farmer field days and forums for information exchange.

4. There is need for special extension agents trained on post-harvest practices been provided to farmers at all levels such as regional, district, ward and village as most of the extension agents have little skills and knowledge on this sector.

5. Appropriate monitoring systems are also crucial in ensuring that frequent extension services are provided to the smallholder farmers as this will facilitate better adoption of post-harvest handling practices and technologies.

6. Farmers should use appropriate post-harvest handling practices to preserve desirable fresh produce quality characteristics and overall post-harvest loss reduction. 
7. Road improvement projects can also play a crucial role towards post-harvest loss reduction in the study areas.

\section{References}

ANR, (2009). Agriculture and Natural Resources (ANR) Policy (2009-2015): The Republic of The Gambia: http://qanet.gm/statehouse/agriculture/achievements.html

Atanda, S. A., Pessu P. O., Agoda S., Isong I. U., \& Ikotun I. (2011). The concepts and problems of post-harvest food losses in perishable crops, African Journal of Food Science, 5(11), 603-61

Babalola, D.A., Megbope, T.A., \& Agbola, P.O. (2008). Post-Harvest Losses in Pineapple Production: A Case Study of Ado-Odo Otta Local Government Area of Ogun State. Bowen Journal of Agriculture, 5, 55-062 and 1597-2836

Dávila, O. G. (2010). Food security and poverty in Mexico: the impact of higher global food prices. Food Security 2, 383-393.

Department of Agriculture. (2013). The Agricultural and Natural Resource Policy, Republic of The Gambia

FAO, (2011). Global food losses and food waste- Extension and prevention. Save Food International Congress. Interpack, Düssledorf, Germany.

Gambia Bureau of Statistics (GBOS) (2013). The Gambia 2013 Population and Housing Census Preliminary Results. Kanifing Institutional Layout P.O. Box 3504, Serrekunda The Gambia. Website: www.gbos.gov.gm.

Gambia National Agricultural Investment Plan (GNAIP), (2011). Government of The Gambia, The Gambia http://www.gafspfund.org/gafsp/sites/gafspfund.org

Hodges R.J., Buzby, J.C., \& Bennett, B. (2011). Postharvest losses and waste in developed and less developed countries: Opportunities to improve resource use. Journal of Agriculture. Sciences. 149, 37-45.

Kader, A.A. (2005). Increasing Food availability by reducing postharvest losses of fresh produce. Acta Horticulturae (ISHS), 682, 2169-2176.

Kitinoja, L. (2010). Identification of appropriate postharvest technologies for improving market access and incomes for small horticultural farmers in Sub-Saharan Africa and South Asia. World Food Logistics Report (WFLO) Final Grant Report, grant number 52198.

Ladaniya, M.S. (2008). Citrus Fruit: biology, technology and evaluation. 67-79 Academic Press, USA.

Louw, A., Jordaan, D., Ndanga, L., \& Kirsten, J.F. (2008). Alternative marketing options for small-scale farmers in the wake of changing agri-food supply chains in South Africa. Agrekon, 47, 287-308.

Martins, R.B., Hogg, T., \& Otero, J.G. (2012). Food handlers' knowledge on food hygiene: The case of a catering company in Portugal. Food Control, 23, 184-190.

Nyangweso, P.M., Odhiambo, M.O., Odunga, P., Korir, M.K., Kipsat, M.J., \& Serem, A.K. (2007). Household food security in Vihiga district, Kenya: determinants of dietary and diversity. African Crop Science conference proceedings, 8, 1383-1389.

Orodho J.A. (2004) Techniques of Writing Research Proposals and Reports in Education, Masda Publishers

Parfitt, J., Barthel, M., \& Macnaughton, S. (2010). Food waste within food supply chains: quantification and potential for change to 2050. Philosophical transactions of the Royal Society of London. Series B, Biological sciences, 365(1554), 3065-3081.

Rahman, M.S. (2007). Handbook of food preservation. Pp. 19-49. CRC Press. 
Rusell, L.F., LeBlanc, D. I., McRae, K. B., \& Ryan, D.A.J. (2009). Losses of vitamin C from fresh strawberries in the commercial supply chain. International Journal of Food Science and Technology, 44, 820-828.

Sablani, S.S., Opara, U.L. \& Al-Balushi, K. (2006). Influence of bruising and storage temperature on vitamin content of tomato fruit. Journal of Food Agriculture \& Environment, 4, 54-58.

Sudheer, K.P., \& Indira, V., (2007). Postharvest technology of horticultural crops. Horticulture Science Series,07, 1-2. Forwarded by Dr. Nawab Ali.New India Publishing.

Vorster, H.H., (2010). The link between poverty and malnutrition: A South African perspective. Health SA Gesondheid, North America. Journal of Interdisciplinary Health Sciences, 15(1), 1-8.

World Bank, (2011). Missing Food: The Case of Postharvest Grain Losses in Sub-Saharan Africa; 60371-AFR; World Bank: Washington, DC, USA.

WRAP (2011). Fruit and vegetables resource maps-Mapping fruit and vegetable waste through the retail and whole sale supply chain. Project code RSC008. 